\title{
Kajian Stok Karbon Organik dalam Sedimen di Area Vegetasi Mangrove Karimunjawa
}

\author{
Nurul Hickmah*, Lilik Maslukah, Sri Yulina Wulandari, Denny Nugroho Sugianto dan \\ Anindya Wirasatriya
}

\author{
Departemen Oseanografi, Jurusan Ilmu Kelautan Fakultas Perikanan dan Ilmu Kelautan \\ Jl. Prof. H. Sudarto, SH Tembalang, Telp/fax (024) 7474698 Semarang 50275 \\ Email: *nurulhickmah@students.undip.ac.id
}

\begin{abstract}
Abstrak
Ekosistem mangrove termasuk ekosistem yang sangat produktif dan dapat berkontribusi sebagai penyimpan karbon organik pada sedimen. Lepasan serasah yang jatuh ke dasar akan menjadi bagian Sedimen. Serasah yang berguguran akan mengalami dekomposisi dan membentuk karbon organik. Jenis mangrove yang tumbuh dalam suatu ekosistem dipengaruhi oleh distribusi ukuran butir. Setiap jenis mangrove memiliki karakteristik pertumbuhan spesifik. Hal ini akan berpengaruh terhadap kemampuan penyimpanan bahan organik dan secara langsung dapat mempengaruhi kontribusi konsentrasi bahan organik dalam sedimen. Penelitian ini bertujuan untuk mengetahui simpanan karbon organik total dalam sedimen di daerah vegetasi mangrove Karimunjawa. Penelitian dilakukan pada 29 September - 3 Oktober 2020. Analisis data meliputi analisis karbon organik total dengan metode LOI (Lost of Ignition), densitas sedimen (Bulk Density), pH sedimen dan ukuran butir sedimen menggunakan metode granulometri. Hasil penelitian menunjukkan rata-rata simpanan karbon organik secara vertikal di dekat aliran sebesar 172,72 ton/ha, sedangkan yang jauh dari aliran yaitu 76,17 ton/ha. Simpanan karbon organik ditentukan oleh variabel terikat yaitu bulk density, kandungan karbon dan kedalaman sampel. Faktor lain yang mempengaruhi simpanan karbon organik yaitu $\mathrm{pH}$ sedimen, ukuran dan jenis partikel.
\end{abstract}

Kata kunci : Distribusi Karbon Organik, Sedimen, Karimunjawa

\begin{abstract}
Mangrove ecosystems are very productive ecosystems and can contribute as organic carbon storages in sediments. The litters that fall into the bottom will be part of sediment. The fallen litters will decompose and form an organic carbon. The type of mangrove that grows in ecosystem is influenced by the grain size distribution. Each type of mangrove has specific growth characteristics. This will affect the ability to storage of organic matter and can directly affect the contribution of organic matter concentration in the sediment. This study aims to determine total organic carbon storage in sediments in mangroves area of Karimunjawa. The study was conducted in $29^{\text {th }}$ September - $3^{\text {rd }}$ October, 2020. The data analysis included analysis of total organic carbon using the LOI (Lost of Ignition) method, sediment density (Bulk Density), sediment's pH and grain size using the granulometric methods. The results showed the average of vertical organic carbon storage near the flow is 172,72 ton/ha, while those far from the flow are 76,17 tons/ha. Organic carbon storage is determined by dependent variables, namely bulk density, carbon's content and sample's depth. The other factors that affect organic carbon storage are sediment's $\mathrm{pH}$, particle's size and type.

Keywords : Organic Carbon Distribution, Sediment, Karimunjawa
\end{abstract}

\section{PENDAHULUAN}

Peningkatan konsentrasi karbon dioksida secara signifikan telah terjadi akibat penggunaan bahan bakar fosil, peningkatan aktivitas industri dan perubahan fungsi lahan (Bates et al., 2012), yang memicu permasalahan bersifat global yaitu pemanasan iklim global. Sejak jaman pra-industri sampai tahun 2011 telah terjadi peningkatan signifikan konsentrasi $\mathrm{C}_{2}$ global di atmosfer dari nilai rerata $278 \mathrm{ppm}$ menjadi 390,5 ppm. Peningkatan $\mathrm{CO}_{2}$ di atmosfer terindikasi sebesar 4,0 GtC Yr${ }^{-1}$ pada abad 21 (IPCC, 2013). Menurut Feely et al. (2009), selama kurun waktu 200 tahun terakhir, laut telah menyerap 525 milyar ton karbon dioksida dari atmosfer yang dihasilkan oleh bahan bakar fosil. Fakta ini menunjukan bahwa laut memiliki peran strategis terhadap stabilitas carbon budget di bumi.

Ekosistem pesisir memainkan peran penting dalam penyimpanan karbon dan sering dikenal sebagai ekosistem biru. Di daerah tropis, ekosistem mangrove dan lamun adalah ekosistem karbon biru utama (Siikamäki et al. 2013). Hutan mangrove merupakan ekosistem peralihan antara daratan dan lautan yang terjadi di sebagian besar sepanjang garis pantai tropis dan subtropis. Indonesia merupakan negara 
kepulauan, sehingga memiliki peran penting dalam penyerap dan penyimpan karbon. Ekosistem mangrove di Indonesia cukup luas yaitu mencapai 2,5-4,25 juta ha, dan luas ekosistem mangrove adalah yang terluas di dunia, mencapai $21 \%$ luas mangrove dunia (Santoso, 2005). Rahmawati et al. (2014) menjelaskan bahwa secara ekologi mangrove berperan dalam penyerap dan penyimpan karbon sehingga sangat penting diperhatikan dalam upaya mitigasi perubahan iklim. Keberadaan ekosistem atau hutan mangrove ini dapat dijadikan sebagai salah satu upaya dalam penurunan kandungan gas $\mathrm{CO}_{2}$ dari atmosfer (Dharmawan dan Siregar, 2008). Selain itu, keberadaan ekosistem ini sangat penting, karena memiliki kontribusi besar sebagai sumber karbon organik terhadap perairan sekitarnya.

Ekosistem mangrove memberikan kontribusi besar dalam kawasan pesisir terhadap penyerapan karbon dari atmosfer melalui penyimpanan karbon yang disimpan dalam bentuk biomassa dan terpendam dalam sedimen. Potensi mangrove dalam menyimpan karbon lebih besar lima kali lipat dibandingkan hutan hujan tropis (Alongi, 2012). Murdiyarso et al. (2015), menjelaskan bahwa simpanan karbon tertinggi pada ekosistem mangrove ditemukan pada bagian sedimen. Sedimen mangrove mempunyai kemampuan dalam penyimpanan karbon yang lebih tinggi dibandingkan penyimpanan karbon pada pohon mangrove itu sendiri (Murray et al., 2011).

Kawasan mangrove di Karimunjawa memiliki luasan yang besar sehingga menjadi sumber produktivitas dalam ekosistem perairan. Hasil dari produktivitas vegetasi mangrove menghasilkan materi organik yang akan mempengaruhi kandungan karbon organik total. Bahan-bahan yang berguguran dari mangrove akan terurai, kemudian menghasilkan bahan organik sehingga akan mempengaruhi kandungan karbon organik pada sedimen mangrove. Lepasan serasah yang jatuh ke dasar akan menjadi bagian dalam sedimen. Serasah yang berguguran akan mengalami dekomposisi membentuk karbon organik. Karbon organik yang tersimpan dalam sedimen dipengaruhi oleh ukuran butir sedimen dan akan berpengaruh terhadap simpanan karbon organik dalam sedimen di ekosistem pesisir. Wahyuningsih et al. (2020) menyatakan bahwa, ukuran dari butir sedimen akan mempengaruhi tingkat penyerapan bahan organik dalam sedimen. Bahan organik akan lebih mudah terikat pada sedimen dengan jenis butir halus yang kemudian akan menghasilkan karbon organik lebih melimpah.

Hasil penelitian Wirasatriya et al. (2020) menjelaskan bahwa Laut Jawa merupakan pelepas karbon. Kondisi ini perlu diimbangi adanya penyerapan karbon oleh ekosistem lain di perairan tersebut. Kepulauan Karimunjawa merupakan salah satu pulau yang terletak di tengah Laut Jawa dan memiliki ekosistem mangrove sehingga ikut berkontribusi dalam menyeimbangkan peran Laut Jawa sebagai penyerap karbon. Pada saat ini beberapa penelitian terkait fungsi ekosistem biru di Karimunjawa telah dilakukan oleh beberapa peneliti antara lain pada ekosistem mangrove oleh Wicaksono (2015), Hartoko et al. (2014), sementara pada ekosistem Lamun telah dilakukan oleh Wirasatriya et al. (2021) dan Hartati et al. (2017) serta pada ekosistem perairan telah dilakukan oleh Fifianingrum et al. (2020). Pada ekosistem mangrove, Wicaksono (2015) dan Hartoko et al. (2014) telah menghitung stok karbon pada biomassa atas tegakan mangrove yang terdiri dari batang, cabang dan daun menggunakan metode penginderaan jarak jauh. Penelitian terkait stok karbon dalam sedimen belum banyak dilakukan. Mengingat lokasi Pulau Karimunjawa berada di laut Jawa, sehingga perlu dilakukan penelitian pada ekosistem pesisir tersebut. Penelitian ini bertujuan menghitung cadangan karbon dalam sedimen dan keterkaitannya terhadap distribusi ukuran butir sedimen. Penelitian ini lebih fokus mengambil lokasi di Pulau Karimunjawa, sehingga dapat melengkapi data simpanan karbon di Pulau Karimunjawa dari yang telah dilakukan sebelumnya oleh Wicaksono (2015). Data simpanan karbon secara vertikal dapat digunakan untuk memperkirakan kontribusi karbon organik oleh mangrove pada beberapa tahun sebelumnya.

\section{MATERI DAN METODE Materi Penelitian}

Materi yang digunakan dalam penelitian ini meliputi data primer dan data sekunder. Data primer pada penelitian berupa konsentrasi karbon organik total (KOT) sedimen di vegetasi mangrove Karimunjawa dan nilai densitas sedimen (Bulk Density). Data sekunder yang digunakan berupa peta Rupa Bumi Indonesia (RBI) tahun 2018, ukuran butir sedimen dan $\mathrm{pH}$ sedimen. 


\section{Metode Penentuan Lokasi}

Metode yang digunakan dalam penentuan titik sampling adalah purposive sampling method. Pengambilan sampel sebanyak 4 titik yaitu lokasi dekat aliran 2 titik (stasiun 135 dan stasiun 181) dan jauh dari aliran 2 titik (stasiun 49 dan stasiun 150). Pada masing-masing titik dilakukan perhitungan simpanan karbon secara vertikal.

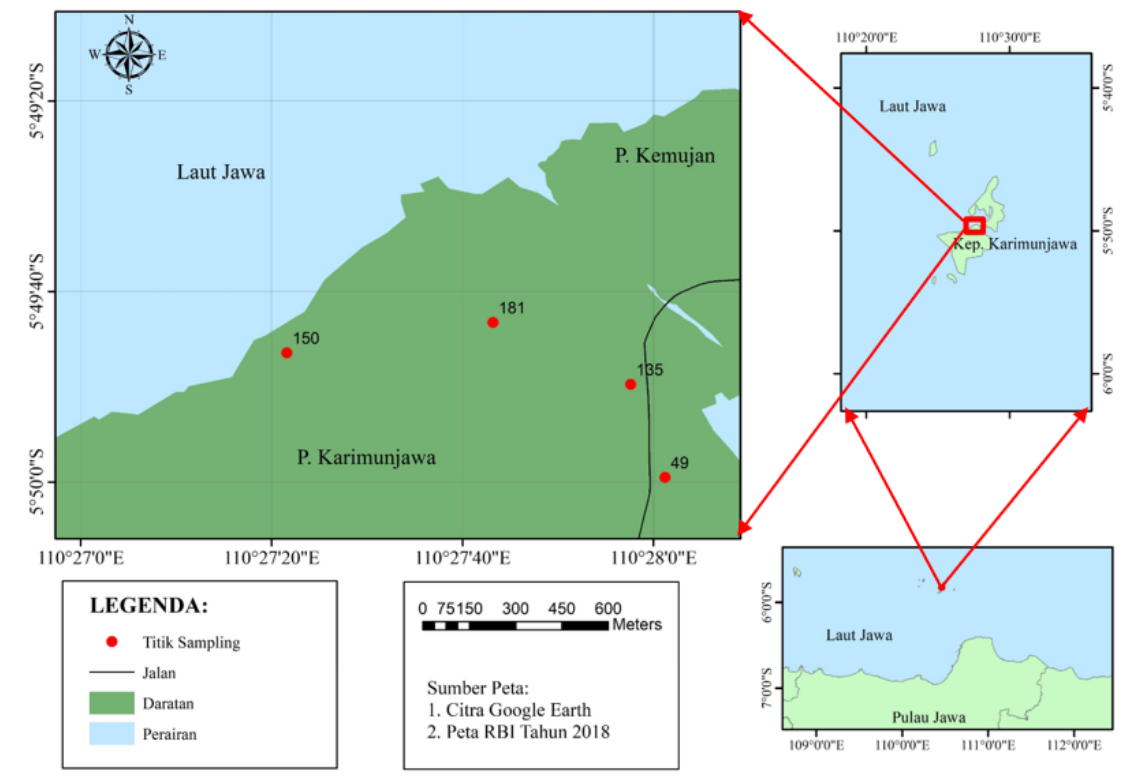

Gambar 1. Titik Lokasi Pengambilan Sampel Penelitian

\section{Metode Pengambilan Sampel Sedimen}

Pengambilan sampel sedimen dilakukan pada tanggal 29 September - 3 Oktober 2020. Sampel sedimen diambil menggunakan pipa polyvinyl chloride (PVC) dengan diameter 7,6 cm dan panjang 100 $\mathrm{cm}$ (Paputungan et al., 2017). Pipa PVC yang telah dimodifikasi sedemikian sehingga memiliki fungsi yang sama dengan sediment core sampler ditancapkan kedalam sedimen hingga kedalaman $30 \mathrm{~cm}$ pada setiap stasiun kemudian dibagi menjadi dua segmen $0-10 \mathrm{~cm}$ untuk sampel atas (A) dan $15-25 \mathrm{~cm}$ untuk sampel bawah (B). Sampel sedimen dimasukkan ke dalam kantong plastik dan diberi label berdasarkan stasiun pengambilan sampel. Sampel-sampel sedimen disimpan pada coolbox untuk dianalisis di laboratorium. Analisis laboratorium meliputi analisis kandungan karbon organik total, tingkat keasaman $(p H)$ sedimen yang diukur menggunakan soil pH meter, densitas sedimen (bulk density) dan ukuran butir sedimen.

\section{Metode Analisis Simpanan Karbon Organik Total}

Sampel yang telah di ambil kemudian dianalisis menggunakan metode Loss on Ignition (LOI) yang mengacu pada metode Analisa Karbon Organik Institute of Marine Organic Geochemistry, Ocean University of China dalam Meng et al. (2014). Sampel sedimen sebanyak 10gram direndam dengan HCL $6 \mathrm{M}$ untuk menghilangkan total inorganic carbon (TIC) dan selanjutnya dibilas dengan aquades dan dikeringkan ke dalam oven. Sampel selanjutnya ditimbang kembali, sebelum dimasukkan ke dalam muffle furnace dan dipanaskan pada suhu 550 $0^{\circ}$ selama 5-6 jam proses pengabuan. Sampel didinginkan di dalam desikator kemudian ditimbang berat akhirnya. Presentase kandungn Karbon Organik Total (KOT) dihitung berdasarkan formula 1.

$$
\text { KOT }=\frac{W o-W t}{W a} \times 100 \%
$$

Keterangan:

wo dan wt adalah berat awal sampel sebelum dan setelah masuk muffle furnace; wa = berat awal sedimen $(10 \mathrm{gr})$ 


\section{Perhitungan nilai Densitas Sedimen (Bulk Density)}

Penentuan Bulk Density didasarkan pada penelitian Elisabeth et al. (2018), dengan cara menimbang bobot sampel sedimen yang dimasukkan kedalam gelas ukur untuk dilihat volumenya dan densitas dihitung menggunakan formula 2.

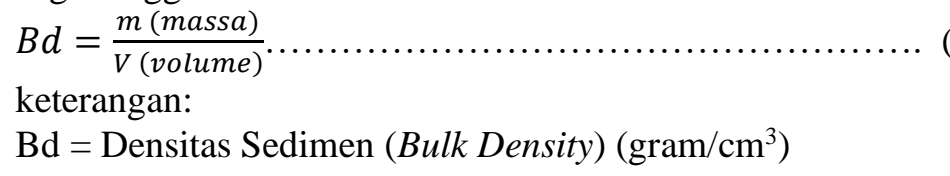

\section{Perhitungan Simpanan Karbon}

Perhitungan simpanan karbon organik sedimen di dasarkan pada penelitian Howard et al. (2014), Adapun perhitungannya menggunakan formula 3.

$$
\begin{aligned}
& C=S D I x \mathrm{Bd} x(\% O C / 100) \\
& \text { keterangan: } \\
& \mathrm{C}=\text { Kerapatan Karbon Sedimen }\left(\mathrm{gram} / \mathrm{cm}^{2}\right)
\end{aligned}
$$

\section{Perhitungan Simpanan Karbon per Hektar}

Perhitungan simpanan karbon organik sedimen per-Hektar di dasarkan pada penelitian Howard et al. (2014). Perhitungan menggunakan formula 4.
Csedimen $=C \times\left(\frac{1 \mathrm{Mg}}{1.000 .000 \text { gram }}\right) \times\left(\frac{100.000 .000 \mathrm{~cm} 2}{1 \mathrm{ha}}\right)$.
keterangan:
Csedimen = Simpanan Karbon Sedimen $(\mathrm{Mg} / \mathrm{ha})$
$* 1 \mathrm{Mg}($ Mega gram $)=1$ Ton
Dengan demikian simpanan karbon organik dapat dituliskan dalam bentuk satuan (ton/ha).

\section{Metode Analisis Jenis dan Ukuran Sedimen}

Metode yang digunakan untuk menganalisis ukuran butir sedimen yaitu dengan metode pengayakan dan dilanjutkan pemipetan untuk ukuran butir >0,625mm (Eleftheriou dan Mc Intyre, 2005).

\section{HASIL DAN PEMBAHASAN}

\section{Karbon Organik} Tabel 1.

Hasil yang diperoleh dari analisis karbon organik di setiap titik pengambilan sampel dapat dilihat pada

Tabel 1. Estimasi Simpanan Karbon Organik Total Secara Vertikal

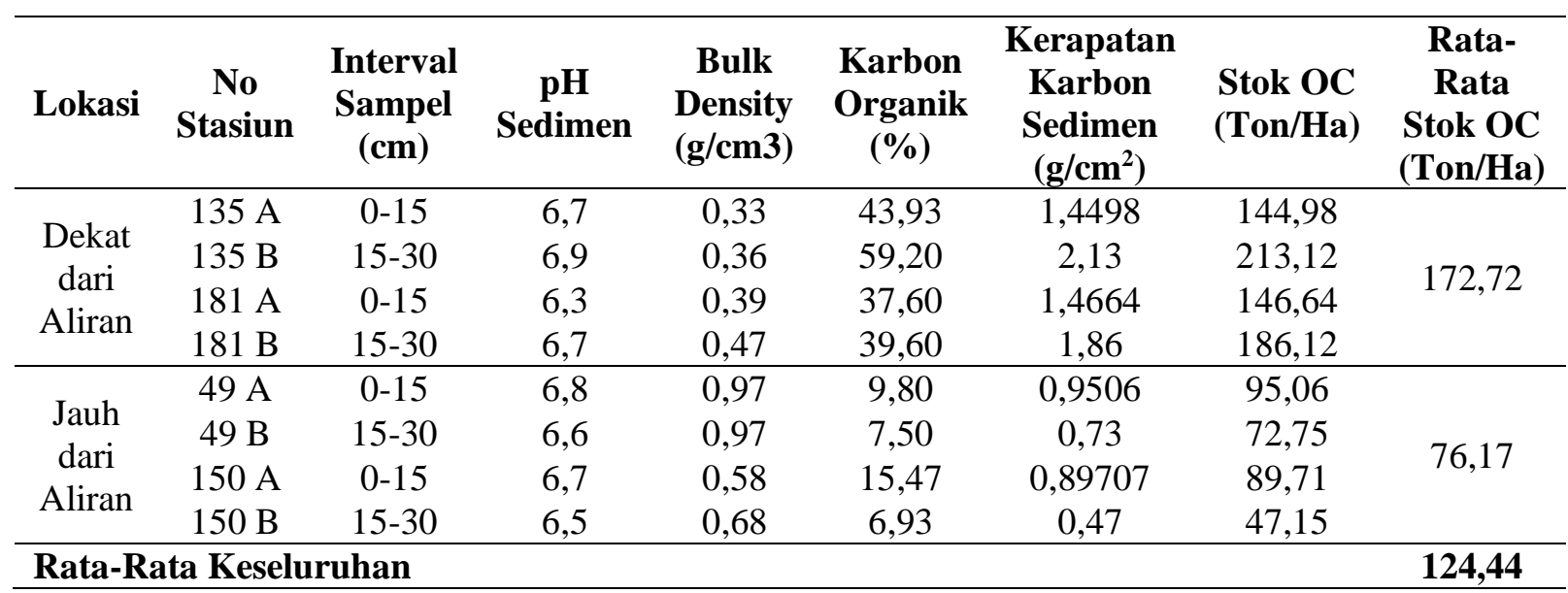

\section{Ukuran Butir dan Jenis Sedimen}

Hasil analisis ukuran butir dan jenis sedimen yang terdapat pada Tabel 2. Sedimen mangrove didominasi oleh jenis sedimen pasir. 
Tabel 2. Ukuran Butir Secara Vertikal

\begin{tabular}{lccccccc}
\hline \multirow{2}{*}{ Lokasi } & $\begin{array}{c}\text { No } \\
\text { Stasiun }\end{array}$ & \multicolumn{2}{c}{ Titik Koordinat } & \multicolumn{3}{c}{ Fraksi Sedimen } & \multirow{2}{*}{ Jenis } \\
\cline { 3 - 6 } & & Lintang $\left({ }^{\circ}\right)$ & Bujur $\left({ }^{\circ}\right)$ & Sand (\%) & $\begin{array}{c}\text { Silt } \\
(\%)\end{array}$ & Clay (\%) & Sedimen \\
\hline \multirow{2}{*}{ Dekat } & 135 A & 5,83049 & 110,46600 & 99,465 & 0,467 & 0,068 & Pasir \\
dari & 135 B & 5,83049 & 110,46600 & 99,655 & 0,304 & 0,041 & Pasir \\
Aliran & 181 A & 5,82868 & 110,46200 & 99,894 & 0,093 & 0,013 & Pasir \\
& 181 B & 5,82868 & 110,46200 & 99,871 & 0,115 & 0,015 & Pasir \\
\hline \multirow{2}{*}{ Jauh } & 49 A & 5,83320 & 110,46700 & 99,866 & 0,113 & 0,020 & Pasir \\
dari & 49 B & 5,83320 & 110,46700 & 99,878 & 0,109 & 0,013 & Pasir \\
Aliran & 150 A & 5,82957 & 110,45600 & 99,853 & 0,127 & 0,020 & Pasir \\
& 150 B & 5,82957 & 110,45600 & 99,866 & 0,124 & 0,010 & Pasir \\
\hline
\end{tabular}

\section{PEMBAHASAN}

Aliran yang terdapat diantara Pulau Karimunjawa dan Pulau Kemujan merupakan sebuah selat pemisah antar pulau. Berdasarkan hasil penelitian didapatkan konsentrasi organik berada pada kisaran 6,93$59,20 \%$. Secara umum, distribusi horisontal konsentrasi karbon organik ditemukan lebih tinggi di lokasi yang dekat aliran (stasiun 135 dan 181) dengan nilai rerata sebesar 45.08\% dibanding stasiun jauh aliran (49 dan 150), dengan nilai rerata 9.93\%. Prosentase nilai karbon organik pada stasiun dekat aliran memiliki nilai lima kali lebih besar dibanding jauh aliran. Hal ini menggambarkan peran sumber air untuk kehidupan mangrove. Tarigan (2008) menjelaskan bahwa hutan mangrove dapat tumbuh dan berkembang baik pada lokasi yang dipengaruhi oleh pengaruh pasang surut dan adanya genangan aliran sungai. Distribusi karbon organik secara horisontal dan vertikal disajikan pada Gambar 2.

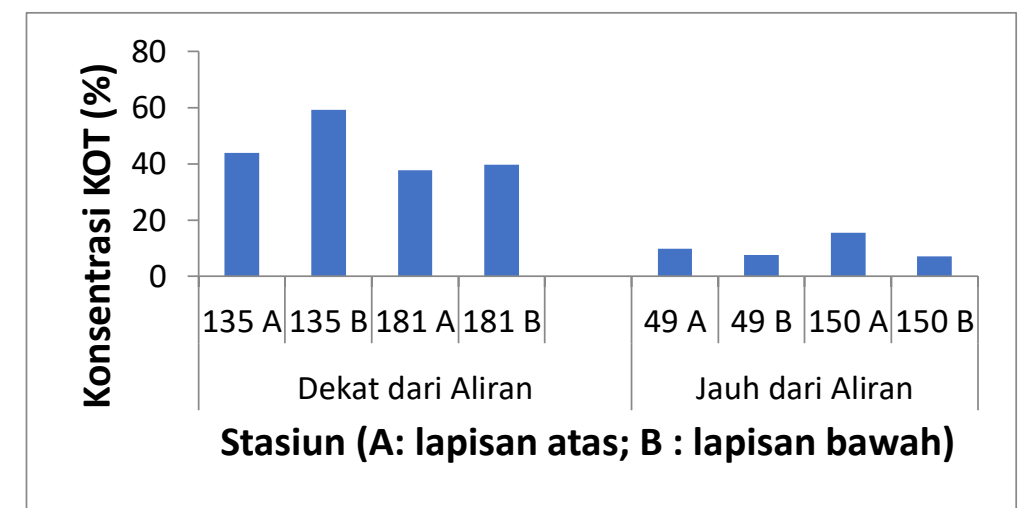

Gambar 2. Distribusi Karbon Organik Total di Pulau Karimunjawa

Berdasarkan Gambar 2, distribusi vertikal menunjukkan bahwa pada lapisan bawah, yaitu pada kedalaman sedimen 15-25 cm memperlihatkan nilai sedikit lebih tinggi di lokasi dekat aliran dibanding lokasi jauh dari aliran. Hal ini diduga berkaitan dengan proses dekomposisi, tingkat sedimentasi dan berkaitan dengan lokasinya yang berada pada dataran lebih rendah. Rendahnya karbon organik di lapisan bawah pada daerah jauh aliran, berkaitan dengan proses dekomposisi lebih tinggi dibanding proses sedimentasi. Proses dekomposisi menyebabkan material organik akan terdekomposisi menjadi senyawa yang lebih sederhana termasuk nutrien. Keberadaan organik karbon dalam sedimen selanjutnya akan menentukan simpanan karbon pada lokasi penelitian.

Simpanan karbon organik dalam sedimen mangrove dapat ditentukan dari parameter lain seperti bulk density dan prosentase karbon organik. Hasil perhitungan menunjukkan bahwa rata-rata simpanan karbon organik pada daerah yang dekat dengan aliran yaitu 172,72 ton/ha dan rata-rata simpanan karbon organik pada lokasi yang jauh dari aliran yaitu 76,17 ton/ha. Secara keseluruhan rata-rata simpanan karbon di lokasi penelitian sebesar 124,44 ton/ha. Nilai ini lebih rendah dibanding hasil penelitian Hermialingga et al. 
(2020) di Pulau Payung, Sumatera Selatan dengan simpanan karbon sedimen sebesar 129,6 ton/ha dan lebih tinggi dari penelitian yang dilakukan oleh Mahasani et al. (2015) di Perancak, Bali dengan simpanan karbon sedimen sebesar 184,618 ton/ha. Simpanan karbon sedimen lebih besar yang dekat aliran daripada simpanan karbon yang jauh dari aliran. Semakin besar kandungan bahan organik dalam sedimen, maka semakin besar pula kandungan karbon organik yang tersimpan, sebaliknya apabila kandungan karbon organik sedimen rendah disebabkan oleh kandungan bahan organik yang ada di dalam sedimen rendah (Mahasani et al., 2016).

Faktor yang mempengaruhi jumlah simpanan karbon organik dalam sedimen mangrove Karimunjawa yaitu $\mathrm{pH}$ sedimen. Berdasarkan hasil penelitian, $\mathrm{pH}$ sedimen mangrove berkisar antara 6,36,9. $\mathrm{pH}$ tersebut masih dalam kategori yang cocok untuk proses dekomposisi bahan organik dalam sedimen mangrove. Sebagaimana menurut Hardjowigeno (1987) dalam Wibowo (2004), bahwa pH dengan kisaran 6,0-7,0 merupakan $\mathrm{pH}$ yang cukup netral dan apabila $\mathrm{pH}$ terlalu masam dapat menyebabkan proses dekomposisi menjadi lambat.

Hubungan antara karbon organik sedimen mangrove dengan ukuran butir sedimen tidak memiliki hubungan korelasi yang kuat. Hal ini disebabkan banyaknya ruang pori makro pada sedimen yang didominasi pasir akan menyebabkan kemampuan menahan air rendah sehingga kerapatan sedimennya rendah. Kondisi demikian menyebabkan sedimen mudah mengalami pencucian sehingga menyebabkan penurunan jumlah karbon organik yang tersimpan dalam sedimen (Mahasani et al. 2015).

\section{KESIMPULAN}

Besarnya nilai simpanan karbon organik ditentukan oleh variabel terikat yaitu bulk density, kandungan karbon organik dan kedalaman sampel. Hasil penelitian menunjukkan rata-rata simpanan karbon organik secara vertikal di dekat aliran sebesar 172,72 ton/ha, sedangkan yang jauh dari aliran yaitu 76,17 ton/ha.

\section{UCAPAN TERIMA KASIH}

Penelitian ini merupakan bagian dari penelitian yang didanai oleh Direktorat Jenderal Penelitian dan Pengembangan, Kementerian Riset, Teknologi, dan Pendidikan Tinggi, Republik Indonesia, di bawah skema "Penelitian Fundamental, Kontrak no. 257-16/UN7.6.1/PP/2020."

\section{DAFTAR PUSTAKA}

Alongi, D. M. 2012. Carbon Sequestration in Mangrove Forest. Carbon Management (3) : 313-322.

Bates, N. R., M. H. P. Best, K. Neely, R. Garley, A. G. Dickson, dan R. J. Johnson. 2012. Detecting anthropogenic carbon dioxide uptake and ocean acidification in the North Atlantic Ocean. Biogeosciences, 9(7).

Dharmawan, I. W. S. dan C. A. Siregar. 2008. Karbon Tanah dan Pendugaan Karbon Tegakan Avicennia marina (Forsk.) Vierh. Di Ciasem, Purwakarta. Jurnal Penelitian Hutan dan Konservasi Alam, 5(4):317-328.

Eleftheriou, A. dan A. M. Intyre. 2005. Methods for the Sudy of Marine Benthos. Ed. 3rd Ed. Blackwell Scientific Publications, Oxford, 422 hal.

Elisabeth, V., P. V. Y. Yamlean dan H. S. Supriati. 2018. Formulasi Sediaan Granul dengan Bahan Pengikat Pati Kulit Pisang Goroho (Musa acuminafe L.) dan Pengaaruhnya pada Sifat Fisik Granul. Jurnal Ilmiah Farmasi, 7(4):1-11.

Feely, R. A., S. C. Doney, dan S. R. Cooley. 2009. Ocean acidification: Present Conditions and Future Changes in a High- $\mathrm{CO}_{2}$ world. Oceanography, 22(4):36-47.

Fifianingrum, K. P. N. D., H. Endrawati dan I. Riniastih. 2020. Simpanan Karbon pada Ekosistem Lamun di Perairan Alang-Alang dan Perairan Pancuran Karimunjawa, Jawa Tengah. Jurnal of Marine Reasearch, 9(3):289-295.

Hartati, R., I. Pratikto dan T. N Pratiwi. 2017. Biomassa dan Estimasi Simpanan Karbon pada Ekosistem Padang Lamun di Pulau Menjangan Kecil dan Pulau Sintok, Kepulauan Karimunjawa. Buletin 
Oseanografi Marina, 6 (1):74-81.

Hartoko, A., S. Chayaningrum, D.A. Febrianti, D. Ariyanto dan Suryanti. 2014. Carbon Biomass Algorithms Development for Mangrove Vegetation in Kemujan, Parang Island Karimunjawa National Park and Demak Coastal Area—Indonesia. Procedia Environmental Sciences, 23:39-47.

Hermialingga, S., R. A. Suwignyo dan T. Z. Ulqodry. 2020. Carbon Storage Estimation In Mangrove Sediment At Payung Island, South Sumatera. Sriwijaya Journal of Environment, 5(3):178-184.

Howard, J., S. Hyot, K. Isensee, E. Pidgeon dan M. Telszewski. 2014. Coastal Blue Carbon: Methods for assessing carbon stocks and emissions factors in mangroves, tidal salt marshes, and seagrasses. Conservation International, Intergovernmental Oceanographic Commission of UNESCO, International Union for Conservation of Nature. Arlington, Virginia, USA.

IPCC. 2013. Climate Change 2013: The Physical Science Basis. Working Group I Contribution to the Fifth Assessment Report of the Intergovernmental Panel on Climate Change, Cambridge University Press, Cambridge, United Kingdom and New York, NY, USA

Mahasani, I. G. A. I., I. W. G. A. Karang dan I. G. Hendrawan. 2016. Karbon Organik di Bawah Permukaan Tanah pada Kawasan Rehabilitasi Hutan Mangrove, Taman Hutan Raya Ngurah Rai, Bali. Prosiding Seminar Nasional Kelautan 2016.

Mahasani, I. G. A. I., N. Widagti dan I. W. G. A. Karang. 2015. Estimasi Persentase Karbon Organik di Hutan Mangrove Bekas Tambak, Perancak, Jembrana, Bali. Jurnal of Marine Aquatic Science, 1:1418.

Meng, J., P. Yao, Z. Yu, T. S. Bianchi, B. Zhao, H. Pan dan D. Li. 2014. Speciation, Bioavailability and Preservation of Phosphorus of the Changjiang Estuary and Adjacent East China Sea Inner Shelf. Estuarine, Coastal and Shelf Science., 144:27-38.

Murdiyarso, D., J. Purbopuspito, J.B. Kauffman, M.W. Warren, S.D. Sasmito, D.C. Donato, S. Manuri, H. Krisnawati, S. Taberima, and S. Kurnianto. 2015. The potential of Indonesian mangrove forests for global climate change mitigation. Nat Geosci., 5:1089-1092.

Murray, B. C., L. Pendleton, W. A. Jenkins dan S. Sifleet. 2011. Green Payments for Blue Carbon: Economic Incentives for Protecting Threatened Coastal Habitats. Nicholas Institute Report.

Paputungan, M. S., A. F. Koropitan, T. Prartono dan A. A. Lubis. 2017. Profil Akumulasi Sedimen di Area Restorasi Mangrove, Teluk Lembar Pulau Lombok. Jurnal Ilmu dan Teknologi Kelautan Tropis, 9(1):301-313.

Rachmawati, D., I. Setyobudiandi dan E. Hilmi. 2014. Potensi Estimasi Karbon Tersimpan pada Vegetasi Mangrove di Wilayah Pesisir Muara Gembong Kabupaten Bekasi. Omni-Akuatika, 13(19): 85-91.

Santoso, N., B. C. Nurcahaya, A. F. Siregar dan I. Farida. 2005. Resep Makanan Berbahan Baku Mangrove dan Pemanfaatan Nipah. Lembaga Pengkajian dan Pengembangan Mangrove. ISSBN: 979-3667-15$\mathrm{X}$.

Siikamäki, J, J. Sanchirico, S. Jardine, D.W. Mc Laughlin and Morris, D. 2013. Blue Carbon: Coastal Ecosystems, Their Carbon Storage, and Potential for Reducing Emissions. Environment: Science and Policy for Sustainable Developmen, 55 (6):14-29.

Tarigan, M.S. 2008. Sebaran dan Luas Hutan Mangrove di Wilayah Pesisir Teluk Pising Utara Pulau Kabaena Provinsi Sulawesi Tenggara. Makara, Sains, 12(2): 108 -112.

Wahyuningsih, A., W. Atmodjo, S. Y. Wulandari, L. Maslukah, dan Muslim. 2020. Distribusi Kandungan Karbon Total Sedimen Dasar di Perairan Muara Sungai Kaliboyo, Batang. 02(01).

Wibowo Edi K, 2004. Beberapa Aspek Bio-Fisik-Kimia Tanah di Daerah Hutan Mangrove Desa Pasar Banggi Kabupaten Rembang. Universitas Diponegoro. Semarang. 
Wicaksono, P. 2015. Pengembangan Model Penginderaan Jauh untuk Pemetaan Stok Karbon Padang Lamun dan Hutan Mangrove. Program Pasca Sarjana, Fakultas Geografi, Universitas Gadjah Mada, Yogyakarta.

Wirasatriya, A., D. N. Sugianto, L. Maslukah, M. F. Ahkam, S. Y. Wulandari dan M. Helmi. 2020. Carbon Dioxide Flux in the Java Sea Estimated from Satellite Measurements. Remote Sensing Applications: Society and Environment, 20: 100376.

Wirasatriya, A., M. N. Nurrahman, L. Maslukah, S. Y. Wulandari, D. N. Sugianto dan N. S. Adi. 2021. Role of the Seagrass Bed at Kemujan Island, Karimunjawa Islands, Indonesia, as a Carbon Sink Area. The International Journal of Climate Change: Impacts and Responses, 14(1). 